COMMENTARY ON COVID-19 AND THE FoOd SYSTEM

\title{
Leveraging informal community food systems to address food security during COVID-19
}

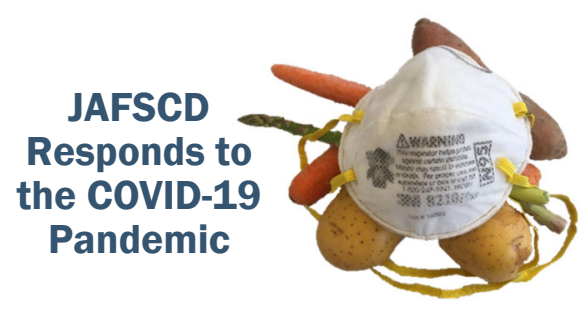

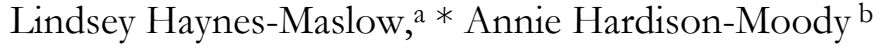 \\ North Carolina State University
}

Carmen Byker Shanks b

Montana State University

\begin{abstract}
Submitted September 11, 2020 / Published online October 19, 2020
Citation: Haynes-Maslow, L., Hardison-Moody, A., \& Byker Shanks, C. (2020). Leveraging informal community food systems to address food security during COVID-19. Journal of Agriculture, Food Systems, and Community Development, 10(1), 197-200. https://doi.org/10.5304/jafscd.2020.101.005
\end{abstract}

Copyright (C 2020 by the Authors. Published by the Lyson Center for Civic Agriculture and Food Systems. Open access under CC-BY license.

$\mathrm{T}$ he novel coronavirus (COVID-19) has dramatically reshaped the U.S. food system and how people interact with it - more specifically, how people interact with their community food environment. The food environment is the distribution of food sources within a community, including the number, type, location, and accessibility of retail food outlets (Glanz, Sallis, Saelens, \& Frank, 2005). Systemic injustices shape our food system and lead to a lack of access to healthier food and beverages for lowincome and communities of color (Baker, Schootman, Barnidge, \& Kelly, 2006; Bower, Thorpe, Rohde, \& Gaskin, 2014). These neighborhood disparities have concrete effects on health, including increasing people's risk for obesity, type 2 diabetes, heart disease, and stroke (Franco, Diez Roux, Glass, Caballero, \& Brancati, 2008; Richardson, Boone-Heinonen, Popkin, \& Gordon-Larsen, 2012). COVID-19 exacerbates these long-standing disparities, disproportionately affecting low-income people and communities of color. Brutal structural inequalities have resulted in Black and Latinx Americans being 2.7 and 3.1,

a * Corresponding author: Lindsey Haynes-Maslow, Associate Professor and Extension Specialist, Department of Agricultural and Human Sciences, North Carolina State University, Raleigh, NC, 27695 USA; +1-919-515-9125; lhaynes-maslow@ncsu.edu

b Annie Hardison-Moody, Associate Professor and Extension Specialist, Department of Agricultural and Human Sciences, North Carolina State University, Raleigh, NC, 27695 USA; annie hardison-moody@ncsu.edu

${ }^{\mathrm{c}}$ Carmen Byker Shanks, Department of Health and Human Development, Food and Health Lab, Montana State University, Bozeman, MT 59718 USA; cbykershanks@montana.edu 
respectively, times more likely to be diagnosed with COVID-19 (Moore et al., 2020).

Given emergent anecdotes about increasing food insecurity and health disparities with the onset of the COVID-19 pandemic, the authors collected statewide data about how individuals in North Carolina accessed and consumed food during the COVID-19 pandemic. ${ }^{1}$ To understand COVID-19's impact on food, we distributed an online Qualtrics survey from May 5, 2020, until June 12, 2020. This study was approved by North Carolina State University's Institutional Review Board. Participants who completed the survey were offered the opportunity to be entered into a raffle to win a US\$100 gift card.

A total of 383 individuals across North Carolina completed the survey. Nearly $84 \%(n=320)$ identified as female, $16 \%(n=61)$ as male, $0.26 \%(n=1)$ as gender queer/gender nonconforming, and $0.26 \%$ $(n=1)$ preferred not to answer. More than $60 \%(n=248)$ were white non-Hispanic/Latino, $27 \%(n=110)$ were Black/African American $(n=110)$, and 5\% $(n=18)$ were Hispanic/Latino.

The findings revealed the dramatic changes in the economic and food landscape of the state. For example, when asked whether participants combined household income would change during the next year as a result of COVID-19, $42 \%(n=160)$ of participants said they would make less money because of COVID-19, and 38\% $(n=145)$ said their income would stay the same. However, $14 \%(n=53)$ preferred not to answer, and $5 \%(n=19)$ said their income would change, but not because of COVID-19. Contrary to popular discourse that many were making more money because of unemployment and stimulus checks (Guina, 2020), only 1.6\% $(n=6)$ of participants stated they would make more money because of COVID-19.

We used the U.S. Department of Agriculture's (USDA) six-item food security screener to understand food security in the study population (USDA ERS, 2020). Food security is defined as "access by all people at all times to enough food for an active, healthy life" (USDA ERS, n.d., para. 1). Participants reported that their food did not last long enough and they did not have money to get more (see Table 1). Other responses generally shifted toward less food security during the pandemic; however, these were not statistically significant.

Table 1. North Carolina Participant Responses to Food Security Status Before and During CoVID-19 $(N=383)$

\begin{tabular}{|c|c|c|c|c|c|c|}
\hline & Before & During & Before & During & Before & During \\
\hline USDA's Six-Item Food Security Screener Questions & \multicolumn{2}{|c|}{ Often True } & \multicolumn{2}{|c|}{ Sometimes true } & \multicolumn{2}{|c|}{ Never true } \\
\hline $\begin{array}{l}\text { The food that my household bought just did not last (not } \\
\text { enough food), and I/we didn't have money to get more. }\end{array}$ & $1.8 \%$ & $7.0 \%$ & $10.4 \%$ & $12.2 \%$ & $83.5 \%$ & $74.4 \%$ \\
\hline I/we couldn't afford to eat balanced meals. & $1.8 \%$ & $6.1 \%$ & $11.3 \%$ & $11.6 \%$ & $82.6 \%$ & $76.2 \%$ \\
\hline $\begin{array}{l}\text { Did you or others in your household ever cut the size of } \\
\text { your meals or skip meals because there wasn't enough } \\
\text { money for food? }\end{array}$ & $2.4 \%$ & $5.5 \%$ & $7.9 \%$ & $10.1 \%$ & $86.0 \%$ & $78.7 \%$ \\
\hline $\begin{array}{l}\text { Did you ever eat less than you felt you should because } \\
\text { there wasn't enough money for food? }\end{array}$ & $2.4 \%$ & $6.1 \%$ & $10.1 \%$ & $9.8 \%$ & $82.6 \%$ & $78.4 \%$ \\
\hline $\begin{array}{l}\text { Were you ever hungry but didn't eat because there wasn't } \\
\text { enough money for food? }\end{array}$ & $1.2 \%$ & $4.6 \%$ & $5.5 \%$ & $7.0 \%$ & $87.5 \%$ & $81.4 \%$ \\
\hline $\begin{array}{l}\text { How often would you say you were worried or stressed } \\
\text { about having enough money to buy nutritious meals? }\end{array}$ & $3.4 \%$ & $7.6 \%$ & $17.7 \%$ & $18.9 \%$ & $74.4 \%$ & $67.7 \%$ \\
\hline
\end{tabular}

a $p$-value $<0.05$

${ }^{1}$ On March 27, 2020 North Carolina's governor issued a stay-at-home executive order to help slow the spread of COVID-19, which was extended until May 8, 2020. North Carolina continues to follow a phased reopening as of this article's publication. 
Despite encountering financial struggles that led to decreasing food security during COVID-19, participants noted the importance of informal networks providing mutual aid that filled the gaps left by federal programs. When asked what food assistance services they received since the start of the pandemic, among 159 responses, even though 51\% $(n=82)$ reported receiving federal food assistance, $15 \%(n=24)$ stated they received food gifts from relatives or friends, $13 \%(n=20)$ relied on alternative food sources (such as personal gardens and wild food harvesting), 11\% $(n=17)$ received food from food banks or pantries, and $6 \%(n=10)$ purchased food from farmers markets or community support agriculture (CSA).

Additionally, we found that participants were overwhelmingly providing support to others in their community during the pandemic. Across 383 participants, 47\% $(n=180)$ picked up and delivered groceries or other essential supplies to family and friends; $31 \%(n=119)$ donated money to a local business or organization; $31 \%(n=117)$ donated food to family or friends; $26 \%(n=101)$ donated money to family or friends, and $17 \%(n=64)$ donated food to a food bank.

Finally, we asked participants what resources about food would be helpful for them during this time. While the most frequently requested resource was centralized information about food availability in their area $(33 \%$ or $n=126), 28 \%(n=108)$ wanted advice on how they could support local food producers, and $26 \%(n=101)$ wanted advice on how to support local food businesses. Lastly, $27 \%(n=103)$ wanted advice on home gardening, and 24\% (n=93) wanted advice on food preservation (canning, freezing, and drying food).

While the federal government scrambled to provide resources and increase flexibility in food assistance programs, our survey reveals that when left on their own, North Carolinians were filling the gaps by providing food support to their families, friends, and local food producers and businesses. In the absence of a national strategy to address the COVID-19 pandemic, study participants relied on their own social networks for support during tough times.

This survey reveals the informal community food systems that exist in families and communities, which during the hardest of times - like the COVID-19 pandemic - help people make ends meet. While participants dealt with their own financial struggles by receiving help from friends, family, and food pantries, these struggles did not prevent them from assisting others in their community. The survey also revealed a strong interest in food sovereignty and local foods-with people naming gardening, canning, and foraging as important food sources during the pandemic.

When the history books are written and studies are published on how COVID-19 interrupted the U.S. food system, we must account for these stories of resilience and community support. Despite their own hardships, and in the face of systemic and persistent inequities, people demonstrated care and support for those in their local communities, highlighting the informal community food systems that exist throughout the U.S.

\section{Acknowledgments}

The authors want to thank all the partner organizations that helped with recruiting participants and the participants for their willingness to respond to our survey.

\section{References}

Baker, E. A., Schootman, M., Barnidge, E., \& Kelly, C. (2006). The role of race and poverty in access to foods that enable individuals to adhere to dietary guidelines. Preventing Chronic Disease, 3(3), A76. PMID: 16776877

Bower, K. M., Thorpe Jr., R. J., Rohde, C., \& Gaskin, D. J. (2014). The intersection of neighborhood racial segregation, poverty, and urbanicity and its impact on food store availability in the United States. Preventive Medicine, 58, 33-39. https://doi.org/10.1016/j.ypmed.2013.10.010 
Franco, M., Diez Roux, A. V., Glass, T. A., Caballero, B., \& Brancati, F. L. (2008). Neighborhood characteristics and availability of healthy foods in Baltimore. American Journal of Preventive Medicine, 35(6), 561-567. https://doi.org/10.1016/j.amepre.2008.07.003

Glanz, K., Sallis, J. F., Saelens, B. E., \& Frank, L. D. (2005). Healthy nutrition environments: Concepts and measures. American Journal of Health Promotion, 19(5), 330-333. https://doi.org/10.4278/0890-1171-19.5.330

Guina, R. (2020). Some earning more money on unemployment than while working: What is their incentive to return to work? Forbes. Retrieved from https://www.forbes.com/sites/ryanguina/2020/04/28/some-earning-more-moneyon-unemployment-than-while-working/

Moore, J. T., Ricaldi, J. N., Rose, C. E., Fuld, J., Parise, M., Kang, G. J., ... \& Honein, M. A. (2020). Disparities in incidence of COVID-19 among underrepresented racial/ethnic groups in counties identified as hotspots during June 5-18, 2020-22 States, February-June 2020. Morbidity and Mortality Weekly Report, 69(33), 1122-1126. https://doi.org/10.15585/mmwr.mm6933e1

Richardson, A. S., Boone-Heinonen, J., Popkin, B. M., \& Gordon-Larsen, P. (2012). Are neighbourhood food resources distributed inequitably by income and race in the USA? Epidemiological findings across the urban spectrum. BMJ Open, 2(2), e000698. https://doi.org/10.1136/bmjopen-2011-000698

U.S. Department of Agriculture, Economic Research Service [USDA ERS]. (n.d.). Food Security in the U.S.: Overview. Retrieved October 8, 2020, from https://www.ers.usda.gov/topics/food-nutrition-assistance/food-security-in-the-us/

USDA ERS. (2020). U.S. Household Food Security Survey Module: Six-item short form. Retrieved from https://www.ers.usda.gov/topics/food-nutrition-assistance/food-security-in-the-us/survey-tools/\#six 